\title{
Type 2 Diabetes Mellitus Profile: Is There a Gender Difference?
}

\author{
Hassanein $\mathrm{S}^{1,3 *}$, Hassan $\mathrm{EG}^{2,3}$, Abdrbo $\mathrm{AA}^{4}$ and Kazim $\mathrm{FA}^{5}$ \\ ${ }^{1}$ Community Health Nursing Department, Faculty of Nursing, Cairo University, Egypt \\ ${ }^{2}$ Medical Surgical Nursing Department, Faculty of Nursing, Cairo University, Egypt \\ ${ }^{3}$ King Saud Bin Abdul-Aziz University for Health Sciences, Al Ahsa, KSA \\ ${ }^{4}$ Nursing Administration Department, Faculty of Nursing, Cairo University, Egypt \\ ${ }^{5}$ Diabetic educator at primary health care center at King Abdulaziz hospital, Al Ahsa
}

\section{Research Article \\ Volume 2 Issue 1}

Received Date: October 26, 2017

Published Date: January 02, 2018

*Corresponding author: Salwa Hassanein, Community Health Nursing Department, Faculty of Nursing, Cairo University, Egypt, Tel: 00966531429281; E-mail: salwa.hassanein@yahoo.com

\section{Abstract}

Diabetes mellitus is viewed as a community health issue. Diabetes mellitus, a chronic and progressive disease, is now becoming one of the most severe illnesses to affect many people worldwide. It has primarily affected the majority of people living in Arabic countries and other countries. The World Health Organization gauges that diabetes mellitus will influence more than 350 million people worldwide by 2030, with the quantity of sufferers being dramatically increased from the year 2000. This study aimed to assess gender differences in the demographic profile as well as to evaluate the gender differences in relation to age, body mass index, activity of daily living, peripheral neuropathic pain, psychological distress, level of knowledge, duration of disease, and vitamin D results. A descriptive cross-sectional correlational design used to collect data from random systematic sample of type 2 diabetes mellitus participants who are attending primary health clinic through face-to-face interview.

The study questionnaires included demographic profile, level of diabetes mellitus knowledge, neuropathic pain symptom inventory, vitamin D status, psychological distress, and functional profile for activities of daily living. There was a positive correlation between duration of type 2 diabetes mellitus for both genders and their age $(r=.21$ for male and $r=.24$ for female, $p=<.01$ ); between peripheral neuropathic pain and psychological distress $(r=.40$ for male and $r=.37$ for female, $\mathrm{p}=<.01)$, and between duration of type 2 diabetes mellitus and diabetes mellitus knowledge only for males $(\mathrm{r}=$ $.14, \mathrm{p}=<.05$ ). Only for female participants, there was a negative correlation between age and diabetes mellitus knowledge $(r=-.23, p=<.01)$, body mass index and vitamin $D$ status $(r=-.27, p=<.01)$, as well as between activity of daily living and peripheral neuropathic pain $(r=-.34, p=<.01)$. For male participants, there was a negative correlation between psychological distress and activity of daily living $(r=-.27, p=<.01)$.

There were positive correlations between duration of DM for both genders and their age; as well as NPSI and 


\section{Nursing \& Healthcare International Journal}

psychological distress. While both genders had a negative correlation between psychological distress and ADL. There were positive correlations between duration of DM and DM knowledge and between duration of DM and NPSI for male participants. Furthermore, there were negative correlations between age and DM knowledge, BMI and vitamin D status, as well as between ADL and NPSI for female participants.

There is a necessity to develop a health educational program that enhance self-management behavior among diabetics that include chronic nature of the disease, glycemic control via home blood glucose monitoring and HbA1c level, dietary guidelines, benefits of physical activity, DM long-term complications, annual check-ups, pain and stress management, and best use of support services.

Keywords: Glycemic; Polyneuropathy; Somatosensory; Diabetes; Progressive Disease

\section{Introduction}

Lately, the number of citizens in Saudi Arabia had experienced noteworthy changes in their ways of life particularly with the expansion in the utilization of innovation. These progressions prompt diminished physical movement and unfortunate dietary patterns, and at last had a noteworthy persuasive effect on the strength of the general public. It is unequivocally felt that this general change in way of life is in charge of the pandemic of non-transmittable infections and their inconveniences in the country [1]. Saudi Arabia titled to be the second nation of the Middle East for Diabetes Mellitus (DM) and it is appraised the seventh of the world [2,3].

DM is viewed as a community health issue. DM, a perpetual and dynamic infection, is currently getting to be plainly a standout amongst the most serious ailments to influence many individuals around the world. It has fundamentally influenced the dominant part of individuals living in Arabic nations and different nations too. By 2030, DM will influence more than 350 million people worldwide with the quantity of sufferers being dramatically increased from the year 2000. The individuals who don't consider this illness important and don't try to treat it, grew long have difficulties and the ailment will in all probability affects the sort 2 Diabetic patient prosperity and societal life $[1,4,5]$.

\section{Significance of the Study}

The Era of gender difference for type $2 \mathrm{DM}$ is scatter. Females with type 2 DM for the most part have unstable control of glycemic and are more averse to achieve the objectives for hemoglobin A1c (HbA1c) contrasted to males [6]. The causes of mortality tended to be higher in females $[7,8]$. Amongst males have type 2 diabetes, the percentage of death in chronic vascular disease had dropped at a rate tantamount with non-diabetic males over the previous year's still there is as yet a very nearly three-overlay increment because of diabetes. While many researchers have included members of both genders, few have dissected for gender contrasts [8,9]. Males are, of any case, extra leaning in imitation of stay consenting according to health center along diabetes-related conditions then because of excessive glucose levels $[8,10]$.

Gender contrasts in the capacity to adapt to existence with DM have been examined by Siddiqui, et al. [11]. Females with type 2 DM seem to passage more terrible mentally, and endure more wretchedness, uneasiness, and low vitality levels contrasted with diabetic males. Females with type 2 DM additionally have high suitability of being depressed than non-diabetic females. Societal class and work status are more grounded indicators of type $2 \mathrm{DM}$ in females than in males in a few [12], yet not all investigations [13]. These variables could conceivably add to the lower level of accomplishment of HbA1c focuses in females contrasted and males. Despite the fact that the predominance of depression and anxiety is higher in females in contrast to males, are more typical among both when compared to type $2 \mathrm{DM}$ in the overall public [14].

The examination uncovered abnormal state of information about critical of checking DM among considered populace, with no noteworthy contrast amongst guys and females [15]. In relation to level of knowledge, there is no significance differences were found between females and males [15]. Regarding diabetic knowledge, dos Santoas, et al. [16]. Concluded that females had exceeded the level of familiarity and awareness for diabetes glucose level parameters, and diabetic complication although diabetic education should be improved for both gender. Additionally, the health care 


\section{Nursing \& Healthcare International Journal}

providers in primary health care setting should prove that type $2 \mathrm{DM}$ patient know about the referral resources and diabetic management strategies [17].

Gaining information regarding determinants of knowledge related to diabetic participants' awareness is the primary step in formulating a health educational program and for further development of different programs that enhance self-management behavior $[17,18]$.

Participants if given appropriate teaching and direction to DM care would be able to have a substantial enhancement in life style, which is supportive for stability and management of glycemic level. Educating diabetic participants will have a significant effect, but only if we can assess their knowledge level, their functional profile (activity of daily living), vitamin D status and psychological wellbeing. Since there are limited researches have been established in Kingdom of Saudi Arabia (KSA) to evaluate the level of information about DM hazard causes and precautionary events, there is a need to investigate the demographic profile, level of diabetes knowledge, neuropathic pain symptoms, vitamin D status, psychological distress, functional profile (activities of daily living) among participants with DM attending Primary Health Clinic at National Guard Health Affairs Hospitals, Eastern Region.

There for the objective of the current study are two folds:

\section{Objectives}

1. Assess gender differences in the demographic profile among participants with type 2 DM who are attending primary health clinic.

2. Evaluate the gender differences in relation to Age, Body Mass Index (BMI), activity of daily living (ADL), peripheral neuropathic pain, psychological distress, level of knowledge, duration of disease, and vitamin D results participants with type $2 \mathrm{DM}$ who are attending primary health clinic.

\section{Literature Review}

DM is a complex, persistent condition that needs both high quality clinical care and effectual self-management. Unfortunately, the prevalence of DM continues to increase at a disturbing rate throughout the world. Therefore, it is highly essential that participants are given selfmanagement education and on-going support in order to accomplish a healthy lifestyle, making these two factors important contributors to metabolic and psychological outcomes among people with DM and those who are at risk of DM $[1,4]$.

With rising occurrence of DM, more type 2 diabetic Patient will need rigorous nutritional management, exercise, and DM medication such as oral drugs and insulin treatment in the primary care clinic. The real problem is to help type 2 diabetic Patient to balance their quality of life against the burden of day-to-day intensive self-management [5].

In 2010, Saudi Arabia ranked third in the global prevalence of type $2 \mathrm{DM}$ and second highest in terms of percentage of national healthcare expenditure on DM [19]. It has been reported that in one of its largest northern districts, Al- Hasa there are 25,100 registered diabetic cases out of a total population of 600,000 . Only $35 \%$ of the diabetic population is appropriately treated or their glycemic levels are stabled [4].

DM is most widely recognized reason for peripheral polyneuropathy. Painful diabetic polyneuropathy was defined as "pain arising as a direct consequence of a lesion or disease affecting the somatosensory system" [20]. Approximately $15-25 \%$ of the cases with diabetic peripheral neuropathy reported neuropathic pain [21]. Diabetic peripheral neuropathy accounts as one of the highest cause for hospital admission amongst those who suffer from DM and is accountable for 50-70 \% of nontraumatic amputations [22].

There was a highly tremendous increase in the occurrence of painful diabetic peripheral neuropathy than anticipated for the last ten years in Saudi Arabia [23,24]. It is proved that peripheral neuropathy is common hazard factor for developing foot ulceration [25].

DM is considered as a chronic illness, which leads to an increased risk of suffering from chronic disability. In comparison between diabetic and non-diabetic patient who are similar in age, several studies reported significant limitation in mobility and additional difficulties in accomplishment of daily living activities among diabetic participants [26]. Diabetic peripheral neuropathy has two effects on daily living activities; firstly, diabetic peripheral neuropathy lead to symptoms of chronic pain and unsteadiness, which predispose to sever functional limitation and diminishing in health- associated quality of life [27-29]. Secondly, diabetic peripheral neuropathy affects the feet to the extent that it may end in complications such as foot ulceration and amputation 


\section{Nursing \& Healthcare International Journal}

which also leads to further limitation in the activity of daily lifting [30].

Studies proved that vitamin D does not just regulate calcium plasma levels but it also has an important role in regulating insulin production and secretion through its effect on pancreatic beta-cell function [31] which improves disorders of glucose and insulin metabolism and secretion. In addition, it was observed in rats that after a single subcutaneous injection of vitamin $\mathrm{D}$, there was an improvement in glucose tolerance and improved insulin secretion. After replacement of vitamin D with calcium supplementation, there was a notable reduction in the fasting glucose level, and insulin resistance as well as improve HbA1c levels in participants with impaired fasting glucose [32-34]. This result was congruent with two randomized controlled studies found that calcium and vitamin $\mathrm{D}$ treatment decrease the risk of type $2 \mathrm{DM}$ $[32,34,35]$. These results support the idea of importance of both calcium and vitamin $\mathrm{D}$ in the management of type 2 DM [36].

DM is a prolonged illness that caused persistent distress over time. It is characterized by everyday 'difficulties' such as restriction in both diet and treatment regimens, that contains recurrent injections, risk of hypoglycemia, complications and frustration of poor control despite stringent adherence $[37,38]$. Moreover Fisher, et al. [39] stated that the everyday psychological stress of living with a chronic disease such as DM and its related psychological distress, accompanying with cyclical unpleasant treatment regimens or the presence of restricting prolonged complications are two interrelated causes of pressure in individual with DM [40].

Stress associated with DM contributes to high rates of anxiety and depression [41]. Nevertheless, distress caused by DM considered the most predominant lifelong aspect associated with hyperglycemia in type 2 DM [42]. Furthermore, the long-term distress may lead to depression putting diabetic participants at a high risk of developing depression although depression itself is a hazard aspect for the progress of DM. Significantly; the presences of the two conditions are accompanied by predominantly poor prognosis and diabetic control and eventually develop more or earlier diabetic complications). Consequently in a diabetes clinic, there is a need for integrated treatment regimen within the management practices to overcome the participants' psychological distress which indicate risk of poor treatment outcomes $[43,44]$.

\section{Methods}

\section{Design}

Descriptive cross-sectional correlational design utilized to accomplish the study aim.

\section{Setting}

Primary health care center at King Abdulaziz hospital, Al Ahsa

\section{Sample}

Random systematic sampling used to recruit type $2 \mathrm{DM}$ participants attending Primary health care Center from the diabetic registry to reach the sample size. Participants should be able to communicate with no barriers such as speech or hearing problems. Using Cohen's [45] conventional parameters, a medium effect size for correlation test $(0.25)$ estimated, an alpha (level of significant) of .05, and a power of .80 [45], the sample size estimated is 200 participants. To overcome the withdrawal and the missing data, an oversampling of 400 participants estimated for the current study.

\section{Data Collection Procedure and Ethical Consideration}

The original questionnaires (demographic profile, level of DM knowledge, neuropathic pain symptom inventory, vitamin D status, psychological distress, and functional profile for activities of daily living) in english were converted into arabic by an expert of both arabic and english. After approval of the institutional review board, consent approval was obtained from the participants before the interview. the researchers explaind clearly to the participants the aim of the study, assuredthem about privacy of their answers and they have the freedom to withdraw from the research at any time withoutany consequences on their treatment.

Face-to-face interview conducted to eliminate the issues of literacy level, visual impairment and opportunity for clarifying any questions in their convenient time. The estimated time for each interview is about 30 minutes per particpant.Additionally, the interviewer has a possibility to check the personal records for lab results if needed.

\section{Instruments}

Demographic profiles: Demographics profiles include the following: individual characteristics (age, gender, BMI, educational level, and family income); disease characteristics (family history, duration of disease); 


\section{Nursing \& Healthcare International Journal}

management of disease (type of medication, dose of medication, duration of insulin intake, frequency of follow up with health educator \& dietitian, blood sugar monitoring, and frequency of examining blood sugar at home); source of diabetic knowledge, presence of disease complication and comorbidity.

DM knowledge questionnaire (DKQ): DM knowledge is defined as the individuals' general awareness of the effect of DM, how DM (type 1 and 2) and pre-diabetes develop, and strategies to prevent and treat the disease [46].

For current study, the 14 items for type 2 DM were used. The questionnaire including: (model blood glucose levels, HbA1c, chronic nature of DM, nutritional recommendations, advantages of bodily activities, Number of occurrences of bodily activities, DM chronic complications, DM foot problems, self-management of blood glucose, ill-day management and yearly check-ups) thus making DKQ a more widely applicable tool. It takes between 5-15 minutes to complete. The Scoring System included one grade per correct answer; 0.5 grade per each 'unsure' answer and no grades for incorrect answers.

Methods to establish content validity was conducted in a Delphi survey of national key of 52 thought leaders that were questioned by email. Eigenmann, et al. (2011) were assessed test-retest reliability, consistency and stability of responses, the whole scores displayed notable reliability with no proof of alteration over time $(\mathrm{t}=1.73$; $\mathrm{df}=56$; $\mathrm{p}<0.85$ ), with a test-retest correlation of 0.62 [46]. Moreover, they orchestrated a pilot study to examine the internal consistency. It was rated good for the first 12 questions (Cronbach's $\alpha=0.73$ ); and the rating of the question about type 1 DM $(\alpha=0.79)$ was fractionally better, just like it was with the extra questions for patients on medication/insulin $(\alpha=0.76)$ [46].

Neuropathic pain symptom inventory (NPSI): Peripheral neuropathic pain in diabetic participants is defined as: "pain arising as a direct consequence of abnormalities in the peripheral somatosensory system in people with DM" [20]. Peripheral neuropathic pain measured by the NPSI. The NPSI is a self-questionnaire that consists of 10 questions to identify the various pain descriptions (e.g. burning, squeezing, electric-shock, stabbing, tingling) that assess various dimensions of neuropathic pain. The questionnaire's items have a review of the previous 24 hours and each item is graded on a $(0-10)$ numerical scale 0 is identified as no symptom and 10 is identified as the worst symptom. The over-all intensity grade (120) is calculated by adding the scores of the 10 questions [47].
The Face validity was established accurately with a mean time period for filling out the questionnaire was less than 7 min [47]. Intra class Correlation Coefficient (ICC) measurement was used to evaluate both the test-retest reliability of items and the total score of the NPSI. ICC was very high $(>0.90)$ for all the items of the test.

Convergent and divergent validity was confirmed with total score of the questionnaire which was associated with the rating of global pain intensity with a numerical scale $((\mathrm{P}=0: 60 ; \mathrm{P}<0: 001)$.

Functional profile for activities of daily living tool: The term "activities of daily living" (ADL) refers to "a set of common, everyday tasks, performance of which is required for personal self-care and independent living" [48]. Functional Profile for Activities of Daily Living tool [49] is a questionnaire designed to measure functional dependency fields in which an individual needs help with daily living activities and determine to which degree they depend on others to assist them. The tool has seven major categories focus on ability of the participants to do regular activities of living that they do at home or in their communities such as; housework, reaching areas beyond walking distance, going shopping, taking their medication, manage their personal finances, walking, and taking a bath or a shower. The participants were asked to answer the seven questions by the following responses: without help (rated 2), with some help (rated 1), or completely unable (rated 0 ). The maximum score of the tool is 14 , a high score indicates a high ability [49].

The validity was demonstrated by a significant relationship between pairs of nurses who rated 36 participants (Pearson correlation of 0.87) and the agreement between two research-assistants who independently rated 14 participants (Pearson correlation was 0.91). The Lawton questionnaire (IADL) was correlated 0.83 with Katz activity of daily living (ADL) [50]. The inter-rater reliability was .85 and the validity reported was confirmed by the correlation with other four scales which assessed functional level domains (correlations were significant at the .01 and .05 level) [51].

Vitamin D status: The measurement values of vitamin D were extracted from the patient record system and the last value of Vitamin D was noted. The most exact approach to scale how much vitamin $D$ level among the participants with type $2 \mathrm{DM}$ is the vitamin D $25 \mathrm{OH}$ test (25-hydroxy vitamin D). According to the hospital laboratory parameters, $75-250 \mathrm{nmol} / \mathrm{L}$ is considered sufficient vitamin $\mathrm{D} ; 25-75 \mathrm{nmol} / \mathrm{L}$ is viewed as 


\section{Nursing \& Healthcare International Journal}

insufficient vitamin D level; and $<25 \mathrm{nmol} / \mathrm{L}$ shows vitamin D deficiency.

Psychological distress scale K10 (Kessler): Psychological distress is often defined as "a distinct concept and is often embedded in the context of strain, stress and distress" [52]. Psychological distress measured by (Kessler Psychological Distress Scale) consistent of 10 questions which used for the early diagnosis of persons who are at risk of or have already developed psychological complications, for example; depression and anxiety, in the four weeks prior to the interview [52].

Each item has a five-level response scale centered on the frequency of a specific problem that the participants experience. This scale includes: (1) none of the time; (2) A little of the time; (3) Some of the time; (4) Most of the time and (5) All of the time. A cut-off score was developed for the Kessler 10: an individual with Low or no risk scores 10 - 15; one with a medium risk scores $16-29$; one with a high risk scores $30-50$. A score of $30+$ signifies the need of a mental health specialist. Reliability tests were also done for the tool, they indicated that K10 was of moderate reliability (the kappa values and weighted kappa scores varied from 0.42 to 0.74 ) [52].

\section{Statistical Analysis}

Descriptive statistics were used to shorten/conclude the data and to describe the research variables. Means and standard deviations were computed for the continuous variables, while numbers and percentages were used for the categorical variables. In addition, T-test and correlation used to describe the differences between genders.

\section{Results}

As shown in (Table 1) of the participants' demographic profile, the average age of male respondents and female respondents was similar (about 41 years old). However, female participants have significant higher duration of the
DM (about 8 years) than male participants (about 7 years). Both genders have family history of DM and the average family members with DM for both were about 23.

There was significant difference between both genders in relation to educational levels. Most of the male participants were primary/intermediate while female participants were mostly illiterate and primary/intermediate educational level. There was also significant difference among both genders in relation to family income. About half of the male participants have 2000-4000 SR family income while more than half of the female participants (55\%) family income was less than 1000 SR.

Regarding management of DM, while about half of the male participants on only oral medication, female participants were mostly on both oral medication and insulin (47.5\%). Insulin injection frequency per day, and follow up with diabetic educator results were similar in both genders. Although fewer participants saw the dietitian, there is a significant difference between both genders with higher percentage of female (18.6\%).

Both genders were taking insulin for less than 5 years and the frequency of taking oral hypoglycemic tablets is mostly one tablet per day. Mostly femaleexamine blood sugar at home and the average of the last blood glucose level for male participants is less than the average of female participants. In relation to Vitamin D status, the average value is insufficient level for male participants while it was deficiency level for female and there is no significant differences between male and female (Table 1).

Both genders regularly measure HbA1c every 3 months and the average of the results is mostly more than eight. Both genders used several sources to get knowledge about DM, mostly had multiple complications and commonly had hypertension as other comorbidity.

\begin{tabular}{|c|c|c|c|c|c|c|}
\hline \multirow{2}{*}{ Variables } & \multicolumn{2}{|c|}{ Male } & \multicolumn{2}{c|}{ Female } & t-test & P-value \\
\cline { 2 - 7 } & Mean & $S D$ & Mean & $S D$ & & \\
\hline Age (years) & 40.93 & 6.82 & 40.55 & 6.93 & 0.53 & 0.59 \\
\hline Duration of DM (years) & 6.91 & 4.82 & 8.21 & 4.96 & -2.58 & 0.01 \\
\hline Number of family members with diabetes & 2.43 & 1.77 & 2.66 & 1.97 & -1.17 & 0.24 \\
\hline Frequency of Insulin injections per day & 2.19 & 0.79 & 2.37 & 0.86 & -1.43 & 0.15 \\
\hline How many times follow up with Diabetic Educator & 2.61 & 1.7 & 2.53 & 1.67 & 0.34 & 0.69 \\
\hline How many times follow up with Dietician & 1.5 & 0.7 & 2.03 & 1.45 & -1.45 & 0.15 \\
\hline Vitamin D Status & 40.29 & 27.03 & 37.67 & 24.45 & 0.76 & 0.44 \\
\hline Variables & \multicolumn{2}{|c|}{ Male } & \multicolumn{2}{|c|}{ Female } & Chi-square & P-value \\
\hline
\end{tabular}




\section{Nursing \& Healthcare International Journal}

\begin{tabular}{|c|c|c|c|c|c|c|c|}
\hline & & $\mathrm{N}$ & $\%$ & $\mathrm{~N}$ & $\%$ & & \\
\hline \multirow{4}{*}{ Level of Education } & Illiterate & 8 & 3.3 & 52 & 31.7 & 76.97 & $<.001$ \\
\hline & Primary/Intermediate & 115 & 48.1 & 72 & 43.9 & & \\
\hline & Secondary/Diploma & 97 & 40.6 & 22 & 13.4 & & \\
\hline & University and Above & 19 & 7.9 & 18 & 11 & & \\
\hline \multirow{4}{*}{ Family Income } & $<1000 \mathrm{SR}$ & 54 & 23.2 & 87 & 55.1 & 42.92 & $<.001$ \\
\hline & $2000-4000 \mathrm{SR}$ & 117 & 50.2 & 51 & 32.3 & & \\
\hline & $5000-10000 \mathrm{SR}$ & 56 & 24 & 16 & 10.1 & & \\
\hline & $>10000 \mathrm{SR}$ & 6 & 2.6 & 4 & 2.5 & & \\
\hline \multirow{2}{*}{ Family History } & Yes & 203 & 86 & 144 & 88.9 & 0.68 & 0.41 \\
\hline & No & 33 & 14 & 18 & 11.1 & & \\
\hline \multirow{5}{*}{ Type of Treatment } & Diet & 5 & 2.1 & 8 & 4.9 & 8.61 & 0.07 \\
\hline & Oral Medication & 118 & 49.8 & 61 & 37.7 & & \\
\hline & Insulin & 14 & 5.9 & 14 & 8.6 & & \\
\hline & Oral Medication and Insulin & 94 & 39.7 & 77 & 47.5 & & \\
\hline & Diet and Oral Medication & 6 & 2.5 & 2 & 1.2 & & \\
\hline \multirow{3}{*}{ Duration of Insulin Intake } & $<5$ years & 61 & 63.5 & 52 & 61.9 & 0.73 & 0.69 \\
\hline & $5-9$ years & 21 & 21.9 & 16 & 19 & & \\
\hline & $>$ Or equal 10 years & 14 & 14.6 & 16 & 19 & & \\
\hline \multirow{3}{*}{$\begin{array}{c}\text { Frequency of oral } \\
\text { Hypoglycaemic per day }\end{array}$} & 1 tablet & 122 & 56.2 & 94 & 65.7 & 3.27 & 0.19 \\
\hline & 2 tablets & 89 & 41 & 45 & 31.5 & & \\
\hline & More than 2 tablets & 6 & 2.8 & 4 & 2.8 & & \\
\hline \multirow{2}{*}{ See Diabetic Educator } & Yes & 163 & 68.8 & 111 & 68.5 & 0.007 & 0.93 \\
\hline & No & 74 & 31.2 & 51 & 31.5 & & \\
\hline \multirow{2}{*}{ See Dietician } & Yes & 19 & 8.3 & 29 & 18.6 & 10.62 & 0.005 \\
\hline & No & 210 & 91.7 & 126 & 80.8 & & \\
\hline \multirow{2}{*}{$\begin{array}{c}\text { Examine Blood Sugar at } \\
\text { home }\end{array}$} & Yes & 129 & 56.1 & 106 & 66.7 & 4.27 & 0.04 \\
\hline & No & 101 & 43.9 & 53 & 33.3 & & \\
\hline \multirow{4}{*}{$\begin{array}{c}\text { Average of the last blood } \\
\text { glucose level at home }\end{array}$} & $<150$ & 52 & 62.7 & 35 & 49.3 & 4.02 & 0.26 \\
\hline & $150-200$ & 28 & 33.7 & 33 & 46.5 & & \\
\hline & $200-300$ & 3 & 3.6 & 2 & 2.8 & & \\
\hline & $>300$ & 0 & 0 & 1 & 1.4 & & \\
\hline \multirow{2}{*}{ Measure HbA1c/3 months- } & Yes & 182 & 76.5 & 124 & 76.5 & 0.001 & 0.97 \\
\hline & No & 56 & 23.5 & 38 & 23.5 & & \\
\hline \multirow{3}{*}{ Average of $\mathrm{HbA} 1 \mathrm{c}$} & $<7$ & 59 & 26.2 & 36 & 23.7 & 0.461 & 0.79 \\
\hline & 8-Jul & 61 & 27.1 & 41 & 27 & & \\
\hline & $>8$ & 105 & 46.7 & 75 & 49 & & \\
\hline \multirow{3}{*}{ Source of Knowledge } & Physician & 47 & 19.8 & 38 & 23.3 & 4.68 & 0.09 \\
\hline & Physician and Diabetic educators & 74 & 31.2 & 63 & 38.7 & & \\
\hline & $\begin{array}{l}\text { Others (Diabetic educators, newspapers, } \\
\text { books, network, friends, or multiple) }\end{array}$ & 116 & 48.9 & 62 & 38 & & \\
\hline \multirow{5}{*}{ Complication of DM } & Kidney damage & 1 & 0.4 & 2 & 1.3 & 3.53 & 0.31 \\
\hline & Retinopathy & 9 & 3.8 & 6 & 3.9 & & \\
\hline & Hyperlipidaemia & 24 & 10 & 24 & 15.5 & & \\
\hline & Multiple & 203 & 84.9 & 123 & 79.4 & & \\
\hline & Heart disease & 4 & 5.8 & 1 & 2.2 & 6.43 & 0.38 \\
\hline
\end{tabular}




\section{Nursing \& Healthcare International Journal}

\begin{tabular}{|c|c|c|c|c|c|c|c|}
\hline \multirow{4}{*}{ Other Comorbidity } & Chronic obstructive lung disease & 1 & 1.4 & 1 & 2.2 & & \\
\cline { 2 - 8 } & Atherosclerosis & 2 & 2.9 & 2 & 4.3 & & \\
\cline { 2 - 9 } & Kidney disease & 3 & 4.3 & 1 & 2.2 & & \\
\cline { 2 - 9 } & Hypertension & 56 & 81.2 & 38 & 82.6 & & \\
\cline { 2 - 8 } & Multiple & 3.3 & 3 & 6.5 & & \\
\hline
\end{tabular}

Table 1: Descriptive Statistics by Gender.

Correlation matrix (Table 2) indicated that there were positive correlations between duration of DM for both genders and their age $(r=.21$ for male and $r=.24$ for female, $\mathrm{p}=.01$ ); between NPSI and psychological distress $(\mathrm{r}=.40$ for male and $\mathrm{r}=.37$ for female, $\mathrm{p}=.01)$. While both genders had a negative correlation between psychological distress and ADL $(r=-.27, p=.01$ for male and $r=-.20, p=.05$ for female).
Only for male participants, there were positive correlations between duration of DM and DM knowledge $(\mathrm{r}=.14, \mathrm{p}=.05)$ and between duration of DM and NPSI ( $\mathrm{r}$ $=.16, \mathrm{p}=.05$ ).

Only for female participants, there were negative correlations between age and DM knowledge $(\mathrm{r}=$ $23, \mathrm{p}=.01)$, BMI and vitamin D status $(\mathrm{r}=-.27, \mathrm{p}=.01)$, as well as between ADL and NPSI $(r=-.34, p=.01)$.

\begin{tabular}{|c|c|c|c|c|c|c|c|c|c|c|c|c|c|c|}
\hline \multirow{2}{*}{ Variables } & \multicolumn{2}{|c|}{ Age } & \multicolumn{2}{|c|}{ BMI } & \multicolumn{2}{|c|}{ ADL } & \multicolumn{2}{|c|}{ NPSI } & \multicolumn{2}{|c|}{$\begin{array}{l}\text { Psychological } \\
\text { Distress }\end{array}$} & \multicolumn{2}{|c|}{\begin{tabular}{|c|} 
DM \\
Knowledge
\end{tabular}} & \multicolumn{2}{|c|}{\begin{tabular}{|c|} 
Duration of \\
DM
\end{tabular}} \\
\hline & M & $\mathbf{F}$ & M & $\mathbf{F}$ & M & $F$ & M & $\mathbf{F}$ & M & $\mathbf{F}$ & $\mathbf{M}$ & $\mathbf{F}$ & M & $\mathbf{F}$ \\
\hline Age & \multicolumn{2}{|c|}{1} & & & & & & & & & & & & \\
\hline BMI & 0.02 & 0.08 & \multicolumn{2}{|c|}{1} & & & & & & & & & & \\
\hline ADL & -0.01 & -0.06 & -0.02 & -0.14 & \multicolumn{2}{|r|}{-} & & & & & & & & \\
\hline NPSI & 0.04 & 0.03 & $-.02^{\prime}$ & -0.07 & -0.08 & $-.34^{* *}$ & \multicolumn{2}{|c|}{1} & & & & & & \\
\hline $\begin{array}{l}\text { Psychological } \\
\text { Distress }\end{array}$ & -0.07 & -0.1 & -0.02 & 0.002 & $-.27 * *$ & $-.20 *$ & $.40^{* *}$ & $.37 * *$ & \multicolumn{2}{|c|}{1} & & & & \\
\hline DM Knowledge & -0.04 & $-.23 * *$ & -0.02 & -0.1 & -0.07 & -0.08 & 0.13 & 0.14 & 0.13 & 0.06 & \multicolumn{2}{|r|}{1} & & \\
\hline Duration of DM & $.21 * *$ & $.24 * *$ & 0.07 & -0.09 & 0.02 & -0.03 & $.16^{*}$ & 0.08 & 0.05 & 0.05 & $.14^{*}$ & 0.1 & \multicolumn{2}{|c|}{1} \\
\hline Vitamin D Status & 0.06 & 0.01 & -0.15 & $-.27 * *$ & 0.02 & 0.05 & 0.04 & 0 & 0.01 & 0 & -0.1 & 0.06 & 0.03 & \\
\hline
\end{tabular}

$* \mathrm{p}=.05, * *=.01$

Table 2: Pearson Correlation Matrix Among the Study Outcome Variables By Gender.

T-test supported the correlation results that indicated female participants had greater average scores in relation to BMI and NPSI. More specific results from t-test indicated that female participants had greater average scores than male participants in relation to their psychological distress. However, male participants had greater average scores in relation to their ADL (Table 3).

\begin{tabular}{|c|c|c|c|c|c|c|}
\hline \multirow{2}{*}{ Variables } & \multicolumn{2}{|c|}{ Male } & \multicolumn{2}{|c|}{ Female } & \multirow{2}{*}{$\mathbf{T}$} & \multirow{2}{*}{ P-value } \\
\hline & Mean & SD & Mean & SD & & \\
\hline BMI & 32.49 & 6.48 & 35.77 & 7.28 & -4.62 & $\mathbf{0}$ \\
\hline DM Knowledge (Total=28) & 17.32 & 4.02 & 17.25 & 4.32 & 0.16 & 0.87 \\
\hline ADL (Total=14) & 13.95 & 0.42 & 13.82 & 0.6 & 2.4 & 0.02 \\
\hline NPSI (Total=100) & 4.61 & 8.35 & 8.27 & 12.9 & -3.35 & $\mathbf{0}$ \\
\hline Psychological Distress (Total=50) & 16.57 & 5.42 & 20.34 & 7.42 & -5.76 & $\mathbf{0}$ \\
\hline
\end{tabular}

Table 3: T-test Results Comparing Males and Females on Study Outcome Variables. 


\section{Nursing \& Healthcare International Journal}

\section{Discussion}

Over the last 20 years, the prevalence of DM has increased among Saudi citizens, in comparison to other countries [53]. It is estimated that 37. $8 \%$ of Saudis, between 30-70 years, suffer from DM [54]. In the present research, the mean age of both genders was about 41 years old. Although Khan and his colleagues [55] reported a higher mean age (57.44 years) in their study in Al-Ahsa. In addition, other studies in different places in KSA observed increase prevalence in the age of 60 years and above $[15,56,57]$.

The results reflected a positive correlation between age and duration of DM for both genders. Different previous researches reported the age as a strong predictor of DM $[58,59]$ due to increase adiposity as consequence of low physical activities [60]. The present study's results revealed that above $80 \%$ of both gender had multiple complications and commonly had hypertension as other comorbidity. In the same line, one Saudi study found that the morbidities which had been reported by the diabetic patients were hypertension, dyslipidemia and heart disease, $49 \%, 28 \%$, and $6 \%$, respectively [5].

Regarding management of diabetes, mostly female examine blood sugar at home and the average of the last blood glucose level for male participants is less than the average of female participants. Those results are in agreement with Chiu and Wray [6] who cited that the females had better self-monitoring for their blood glucose level than the males.

Both genders regularly measure HbA1C every 3 months and the average of the results is mostly more than 8 . Previous studies (2005-2011) revealed that the female had bad glycemic control and increasing fat deposition, micro vascular complications and high blood pressure [61,62]. A recent German finding [63] indicated that the percentage of males with poor glycemic control (37\%) was higher than the female percentage $(19 \%)$ as well as another study stated that males had a higher admission rate to hospital due to high blood sugar or conditions related to diabetes [64].

In the present study, both genders reported minor neuropathic pain (4.61 male and 8.27 female) that may be due to the fact that most of the participants experienced DM less than 10 years; the mean average of duration of DM between male and females was 6.91 and 8.21 respectively. Longer duration of DM (more than 10 years), older age and lack of glycemic control are significant predictors for the occurrence of peripheral neuropathy pain among patients with DM in the Middle East countries [65,66]; and western countries [65,67].

The analysis of data showed a positive direct correlation between NPSI and psychological distress in both genders. Many researchers conducted among different populations, supported that neuropathic pain enhances the burden on diabetic patients due to its high impairment of the patients' functions, as well as their quality of life $[27,28,68]$. Furthermore, another investigation signified the presence of a relationship between diabetic neuropathy pain and symptoms of depression among patients who complain from diabetic peripheral neuropathy [69]. Signs of depression and anxiety were observed more frequently among both diabetic males and females, in comparison to the public [14]. However, previous studies found that diabetic females demonstrated more anxiety, depression, and low energy than their male counterparts did $[8,70]$.

Another finding revealed a negative correlation between psychological distress and ADL for both genders. While male subjects had significant higher, mean score than female subjects. Diabetics may develop notable levels of psychological distress because of having to cope with the disease obligations such as; strict dietary management, adherence to medications, physical exercise, and periodic checkups [11] as well as having to carry the burden of potential diabetic complications. In consequence, the excessive psychological distress affects the patient's life style and habits [71]. To further support the finding, decreases in ADL caused by non-psychological factors (physical diabetic complications), are associated with depression due to their adverse impacts on males' different social roles [69].

For male' participants only, the results showed a positive correlations between duration of DM and both their DM knowledge and NPSI. This might be because increasing the duration of treatment; the patients will contact their health care providers (physician, diabetic educator as well as dietician) more, which will give them more opportunities to gain knowledge. This finding is consistent with different studies that were done in Ethiopia, Nigeria, and South Africa, where they found that increasing the length of DM management lead to an increase in the patients' knowledge [72-74]. However, another study at a veteran's affairs medical centre reported no significance relation between knowledge and the length of DM treatment [75]. In addition, previous studies indicated that duration of 10 years and more is the greatest indicator of painful peripheral neuropathy among diabetic patients [27-29]. 


\section{Nursing \& Healthcare International Journal}

For females' participants, the results reflected an inverse correlation between NPSI and ADL. Two earlier studies supported this finding by reporting that diabetic neuropathy pain leads to restrictions in the activities of daily living (ADLs) and performance incompetency of diabetic females' social family role, thereby, causing the feeling of self-value [76,77]. In the current study, the female participants had significant higher mean score for psychological distress than male participants. A study showed that diabetic females instinctively care for their families more than themselves, and therefore still provide for their families, even when in agony [11].

Another finding revealed a negative correlation between DM knowledge and age among females only. This may be explained by educational status, as most of the female participants $(75.6 \%)$ had a low level of education; either illiterate $(31.7 \%)$ or at primary/intermediate level (43.9\%). This finding offered support to the earlier study which assessed the information about DM threat factors among diabetics in eastern region of KSA, the results showed that age had an inverse association with knowledge (odds ratio 0.377, 95\% CI 0.207$0.685, \mathrm{P}=.001$ ) [78]. Interestingly, this relationship between knowledge and age had been found also in different earlier study that investigated the connection between age and the patients' knowledge about cardiac disease [79]. On the contrary, different recent studies in various settings confirmed that females had more knowledge about DM than males [16,80-82]. In Jazan, a studyshowed that there is no difference between diabetics of both gender, regarding the level of knowledge [15], although, another study in Al-Qassim reported that males had better knowledge about DM, than females (OR $0.569 ; 95 \%$ CI 0.471 to 0.687 ) [83].

The last finding identified inverse association between BMI and vitamin D status among females only and vitamin D level amongst them were decreased. The relation between gaining weight and having low levels of vitamin D, was reported in earlier studies $[84,85]$. Another study found that an increase in BMI causes a reduction in $25(\mathrm{OH}) \mathrm{D}$, but, a reduction in 25(OH)D will not affect BMI influentially [86]. Further researchers also found that a decrease in vitamin $\mathrm{D}$ was dependably linked to sex, increase in weight (due to type $2 \mathrm{DM}$ ), age, metabolic syndrome, and insulin resistance $[87,88]$. Additionally, the prevalence of abdominal obesity increases among type 2 DM patients with higher occurrences among females (70\%) than males (40\%) [89]. Moreover, an upto-date study that took place in Saudi Arabia, stated an apparent vitamin $\mathrm{D}$ deficiency among diabetic patients $(\mathrm{p}$ $<0.001$ ) of both genders [90].

\section{Conclusion}

There were positive correlations between duration of DM for both genders and their age; as well as NPSI and psychological distress. While both genders had a negative correlation between psychological distress and ADL. There were positive correlations between duration of DM and DM knowledge and between duration of DM and NPSI for male participants. Furthermore, there were negative correlations between age and DM knowledge, BMI and vitamin D status, as well as between ADL and NPSI for female participants.

\section{Limitations}

Limitations of the study included the use of crosssectional design which focus on one point of time data collection as well as using the self-report measures which may affect the consistency of the responses from the participants. The results of this study generalized only for primary health care centres attendants. The current study is topical in nature which limit the availability of more studies to rigor the discussion of the study.

\section{Implications and Recommendations}

There is a need for regular screening for psychological distress, NPS and its associated effect on the ADL, low DM knowledge, higher BMI, and low vitamin D status among diabetic females as well as developing an individualized plan for management and coping strategies.

The study results reinforced that there is a need for alerting the health care team for the importance of regularly assessing the occurrence of peripheral neuropathy among participants who have DM using a simple, impartial, reproducible, and comprehensive tool.

There is a necessity to develop a health educational program that enhance self-management behavior among diabetics that include chronic nature of the disease, glycemic control via home blood glucose monitoring and HbA1c level, dietary guidelines, benefits of physical activity, DM long-term complications, annual check-ups, and best use of support services.

It is recommended to follow up with the diabetics from different primary health care centers using longitudinal study design to investigate the disease changes over time, life style changes and adherence to management regimen among diabetics. In addition, to assess the utilization and effectiveness of health care services at primary health 


\section{Nursing \& Healthcare International Journal}

care centers such as psychiatrics, podiatrist, dietitian, and diabetic educators.

\section{References}

1. Khan AR, Abdul Lateef ZNA, Khamseen MB, Al Aithan MA, Khan SA, et al. (2011) Knowledge, attitude and practice of ministry of health primary health care physicians in the management of type 2 diabetes mellitus: A cross-sectional study in the Al Hasa District of Saudi Arabia, 2010. Nigerian journal of clinical practice 14(1): 52-59.

2. Al Dawish MA, Robert AA, Braham R, Al Hayek AA, Al Saeed A, et al. (2016) Diabetes mellitus in Saudi Arabia: a review of the recent literature. Curr Diabetes Rev 12(4): 359-368.

3. WHO (2014) Global status report on alcohol and health, World Health Organization.

4. Khan AR, Wiseberg JA, Lateef ZAA, Khan SA (2010) Prevalence and Determinants of Diabetic Retinopathy in Al Hasa Region of Saudi Arabia: Primary Health Care Centre Based Cross-Sectional Survey, 20072009. Middle East Afr J Ophthalmol 17(3): 257-263.

5. Ahmed NO, Abugalambo S, Almethen GH (2017) Adherence to oral hypoglycemic medication among patients with diabetes in Saudi Arabia. Int J Health Sci Qassim 11(3): 45-49.

6. Chiu CJ, Wray LA (2011) Gender differences in functional limitations in adults living with type 2 diabetes: biobehavioral and psychosocial mediators. Annals of Behavioral Medicine 41(1): 71-82.

7. Roche MM, Wang PP (2013) Sex differences in allcause and cardiovascular mortality, hospitalization for individuals with and without diabetes, and patients with diabetes diagnosed early and late. Diabetes Care 36(9): 2582-2590.

8. Arnetz L, Ekberg NR, Alvarsson M (2014) Sex differences in type 2 diabetes: focus on disease course and outcomes. Diabetes, metabolic syndrome and obesity: targets and therapy 7: 409-420.

9. Legato MJ, Gelzer A, Goland R, Ebner SA, Rajan S, et al. (2006) Gender-specific care of the patient with diabetes: review and recommendations. Gender Medicine 3(2): 131-158.
10. Shen JJ, Samson LF, Washington EL, Johnson P, Edwards C, et al. (2006) Barriers of HIPAA Regulation to Implementation of Health Services Research. Journal of Medical Systems 30(1): 65-69.

11. Siddiqui MA, Khan MF, Carline TE (2013) Gender differences in living with diabetes mellitus. Mater Sociomed 25(2): 140-142.

12. Müller G, Hartwig S, Greiser KH, Moebus S, Pundt N, et al. (2013) Gender differences in the association of individual social class and neighbourhood unemployment rate with prevalent type 2 diabetes mellitus: a cross-sectional study from the DIAB-CORE consortium. BMJ open 3(6).

13. Eriksson AK, Ekbom A, Granath F, Hilding A, Efendic S, et al. (2008) Psychological distress and risk of pre-diabetes and Type 2 diabetes in a prospective study of Swedish middle-aged men and women. Diabetic Medicine 25(7): 834-842.

14. Svenningsson I, Björkelund C, Marklund B, Gedda B (2012) Anxiety and depression in obese and normal-weight individuals with diabetes type 2: A gender perspective. Scand J Caring Sci 26(2): 349354.

15. Bani IA (2015) Prevalence, knowledge, attitude and practices of diabetes mellitus among Jazan population, Kingdom of Saudi Arabia (KSA). Journal of Diabetes Mellitus 5(2): 115-122.

16. dos Santos PFL, dos Santos PR, Ferrari GSL, Fonseca GAA, Ferrari CKB (2014) Knowledge of diabetes mellitus: Does gender make a difference? Osong Public Health Res Perspect 5(4): 199-203.

17. Powers MA, Bardsley J, Cypress M, Duker P, Funnell MM et al. (2017) Diabetes self-management education and support in type 2 diabetes: a joint position statement of the American Diabetes Association, the American Association of Diabetes Educators, and the Academy of Nutrition and Dietetics. The Diabetes Educator 43(1): 40-53.

18. Saadia Z, Rushdi S, Alsheha M, Saeed H, Rajab M (2009) A Study Of Knowledge Attitude And Practices Of Saudi Women Towards Diabetes Mellitus. A (KAP) Study in Al-Qassim Region. The Internet Journal of Health 11(2). 


\section{Nursing \& Healthcare International Journal}

19. Kalyani RR, Saudek CD, Brancati FL, Selvin E (2010) Association of diabetes, comorbidities, and A1C with functional disability in older adults: results from the National Health and Nutrition Examination Survey (NHANES), 1999-2006. Diabetes Care 33(5): 10551060.

20. Treede RD, Jensen TS, Campbell JN, Cruccu G, Dostrovsky JO, et al. (2008) Neuropathic pain Redefinition and a grading system for clinical and research purposes. Neurology 70(18): 1630-1635.

21. Davies M, Brophy S, Williams R, Taylor A (2006) The prevalence, severity, and impact of painful diabetic peripheral neuropathy in type 2 diabetes. Diabetes Care 29(7): 1518-1522.

22. Gu Y, Dennis SM (2017) Are falls prevention programs effective at reducing the risk factors for falls in people with type- 2 diabetes mellitus and peripheral neuropathy: A systematic review with narrative synthesis. Journal of diabetes and its complications 31(2): 504-516.

23. Akbar DH, Mira SA, Zawawi TH, Malibary HM (2000) Subclinical diabetic neuropathy. Saudi Medical Journal 21(5): 433-437.

24. Halawa MR1, Karawagh A, Zeidan A, Mahmoud AE, Sakr M, et al. (2009) Prevalence of painful diabetic peripheral neuropathy among patients suffering from diabetes mellitus in Saudi Arabia. Curr Med Res Opin 26(2): 337-343.

25. Piemontese M, Meyr A (2010) Current and Emerging Tools for Assessing Diabetic Peripheral Neuropathy. Podiatry Today 23(5): 16-23.

26. Lu FP, Lin KP, Kuo HK (2009) Diabetes and the risk of multi-system aging phenotypes: a systematic review and meta-analysis. PLoS One 4(1).

27. McDermott AM, Toelle TR, Rowbotham DJ, Schaefer CP, Dukes EM (2006) The burden of neuropathic pain: results from a cross-sectional survey. Eur J Pain 10(2): 127-135.

28. Jensen MP, Chodroff MJ, Dworkin RH (2007) The impact of neuropathic pain on health-related quality of life Review and implications. Neurology 68(15): 1178-1182.
29. O'Connor AB (2009) Neuropathic pain: quality-of-life impact, costs and cost effectiveness of therapy. Pharmacoeconomics 27(2): 95-112.

30. Gul I, Gul S, Dar MA, Ali A, Ashraf A, et al. (2017) Prevalence Of Peripheral Neuropathy And Pattern Of Involvement On Nerve Conduction Study In Patients of Type 2 Diabetes Mellitus With Clinical Symptoms Of Peripheral Neuropathy In Kashmiri Population A Hospital Based Study. Imperial Journal of Interdisciplinary Research 3(2).

31. Palomer X, Gonzalez Clemente JM, Blanco Vaca F, Mauricio D (2008) Role of vitamin D in the pathogenesis of type 2 diabetes mellitus. Diabetes Obes Metab 10(3): 185-197.

32. Pittas AG, Harris SS, Stark PC, Dawson-Hughes B (2007) The effects of calcium and vitamin D supplementation on blood glucose and markers of inflammation in nondiabetic adults. Diabetes Care 30(4): 980-986.

33. Danescu LG, Levy S, Levy J (2009) Vitamin D and diabetes mellitus. Endocrine 35(1): 11-17.

34. Farrokhian A, Raygan F, Bahmani F, Talari HR, Esfandiari R, et al. (2017) Long-Term Vitamin D Supplementation Affects Metabolic Status in Vitamin D-Deficient Type 2 Diabetic Patients with Coronary Artery Disease. The Journal of Nutrition 147(3): 384389.

35. de Boer IH, Tinker LF, Connelly S, Curb JD, Howard $\mathrm{BV}$, et al. (2008) Calcium plus vitamin D supplementation and the risk of incident diabetes in the Women's Health Initiative. Diabetes Care 31(4): 701-707.

36. Krul Poel Y, Ter Wee M, Lips P, Simsek S (2017) The effect of vitamin D supplementation on glycaemic control in patients with type 2 diabetes mellitus: a systematic review and meta-analysis. The Role of Vitamin D In Glycaemic Control 145.

37. Wilhelm K, Gillis I, Reddy J, Mitchell PB, Campbell L, et al. (2012) Association between serotonin transporter promoter polymorphisms and psychological distress in a diabetic population. Psychiatry Res 200(2-3): 343-348.

38. Indelicato L, Dauriz M, Santi L, Bonora F, Negri C, et al. (2017) Psychological distress, self-efficacy and glycemic control in type 2 diabetes. Nutrition, 


\section{Nursing \& Healthcare International Journal}

Metabolism and Cardiovascular Diseases 27(4): 300306.

39. Fisher L, Mullan JT, Skaff MM, Glasgow RE, Arean P, et al. (2009) Predicting diabetes distress in patients with Type 2 diabetes: a longitudinal study. Diabet Med 26(6): 622-627.

40. Zaidi SMIH, Yaqoob N, Saleem R, Fatima A (2017) Psychological Distress and Disease: Level Of Stress In Victims Of Type 2 Diabetes Mellitus. Journal of Postgraduate Medical Institute (Peshawar-Pakistan) 31(1).

41. Aikens JE, Perkins DW, Lipton B, Piette JD (2009) Longitudinal analysis of depressive symptoms and glycemic control in type 2 diabetes. Diabetes Care 32(7): 1177-1181.

42. Gois C, Akiskal H, Akiskal K, Figueira ML (2012) Depressive temperament, distress, psychological adjustment and depressive symptoms in type 2 diabetes. J Affect Disord 143(1-3): 1-4.

43. Gonzalez JS, Fisher L, Polonsky WH (2011) Depression in diabetes: have we been missing something important? Diabetes Care 34(1): 236-239.

44. Haider Zaidi SMI, Yaqoob N, Saleem R, Fatima A (2017) Psychological Distress And Disease: Level Of Stress In Victims Of Type 2 Diabetes Mellitus. Jpmi: Journal of Postgraduate Medical Institute 31(1).

45. Cohen J (1988) Statistical power analysis for the behavioral sciences, $2^{\text {nd }}$ (Edn.), Lawrence Erlbaum.

46. Eigenmann C, Skinner T, Colagiuri R (2011) Development and validation of a diabetes knowledge questionnaire. Practical Diabetes International 28(4): 166-170d.

47. Bouhassira D, Attal N, Fermanian J, Alchaar H, Gautron M, et al. (2004) Development and validation of the neuropathic pain symptom inventory. Pain 108(3): 248-257.

48. Wiener JM, Hanley RJ, Clark R, Van Nostrand JF (1990) Measuring the activities of daily living: Comparisons across national surveys. Journal of Gerontology 45(6): S229-S237.

49. Eagar K, Owen A, Green J, Cromwell D, Poulos R, et al. (2002) A national measure of functional dependency for Home and Community Care Services in Australia.
Aged and Community Care Service Development and Evaluation Reports (41).

50. Lawton MP, Brody EM (1969) Assessment of older people: self-maintaining and instrumental activities of daily living. Gerontologist 9(3): 179-186.

51. Graf C (2008) The Lawton instrumental activities of daily living scale. Am J Nurs 108(4): 52-62.

52. Andrews G, Slade T (2001) Interpreting scores on the Kessler psychological distress scale (K10). Australian and New Zealand journal of public health 25(6): 494497.

53. Al Hayek AA, Robert AA, Al Dawish MA, Zamzami MM, Sam AE, et al. (2013) Impact of an education program on patient anxiety, depression, glycemic control, and adherence to self-care and medication in Type 2 diabetes. Journal of Family \& Community Medicine 20(2): 77-82.

54. Al Rubeaan K, Abu El Asrar AM, Youssef AM, Subhani SN, Ahmad NA, et al. (2015) Diabetic retinopathy and its risk factors in a society with a type 2 diabetes epidemic: a Saudi National Diabetes Registry-based study. Acta Ophthalmol 93(2).

55. Khan AR, Lateef ZNAA, Fatima S, Al Yousuf SAA, Afghan SZK, et al. (2014) Prevalence of chronic complication among type 2 diabetics attending primary health care centers of $\mathrm{Al}$ Ahsa district of Saudi Arabia: a cross sectional survey. Global journal of health science 6(4): 245-253.

56. Al-Nozha MM, Al-Maatouq MA, Al-Mazrou YY, AlHarthi SS, Arafah MR, et al. (2004) Diabetes mellitus in saudi arabia 25(11): 1603-1610.

57. Al-Daghri NM, Al-Attas OS, Alokail MS, Alkharfy KM, Yousef M, et al. (2011) Diabetes mellitus type 2 and other chronic non-communicable diseases in the central region, Saudi Arabia (Riyadh cohort 2): a decade of an epidemic. BMC medicine 9: 76.

58. Thabit H, Burns N, Shah S, Brema I, Crowley V, et al. (2013) Prevalence and predictors of diabetes and cardiometabolic risk among construction workers in Ireland: the Construction Workers Health Trust screening study. Diabetes and Vascular Disease Research 10(4): 337-345.

59. Bahijri SM, Jambi HA, Al Raddadi RM, Ferns G, Tuomilehto J (2016) The prevalence of diabetes and 


\section{Nursing \& Healthcare International Journal}

prediabetes in the adult population of Jeddah, Saudi Arabia-a community-based survey. PloS one 11(4).

60. Kahn SE, Hull RL, Utzschneider KM (2006) Mechanisms linking obesity to insulin resistance and type 2 diabetes. Nature 444(7121): 840-846.

61. Szalat A, Raz I (2007) Gender-specific care of diabetes. Women's Health 3(6): 735-764.

62. Tang YH, Pang S, Chan MF, Yeung GS, Yeung VT (2008) Health literacy, complication awareness, and diabetic control in patients with type 2 diabetes mellitus. J Adv Nurs 62(1): 74-83.

63. Raum E, Krämer HU, Rüter G, Rothenbacher D, Rosemann T, et al. (2012) Medication non-adherence and poor glycaemic control in patients with type 2 diabetes mellitus. Diabetes Res Clin Pract 97(3): 377384.

64. Washington EL, Shen JJ (2006) Gender discrepancies in the level of disease progression in hospitalized patients with diabetes. Manag Care Interface 19(10): 21-25.

65. Jambart S, Ammache Z, Haddad F, Younes A, Hassoun A, et al. (2011) Prevalence of painful diabetic peripheral neuropathy among patients with diabetes mellitus in the Middle East region. J Int Med Res 39(2): 366-377.

66. Al-Mahroos F, Al-Roomi K (2007) Diabetic neuropathy, foot ulceration, peripheral vascular disease and potential risk factors among patients with diabetes in Bahrain: a nationwide primary care diabetes clinic-based study. Ann Saudi Med 27(1): 2531.

67. Smith AG, Singleton JR (2008) Impaired glucose tolerance and neuropathy. Neurologist 14(1): 23-29.

68. O'Connor AB (2009) Neuropathic pain. Pharmacoeconomics 27(2): 95-112.

69. Vileikyte L, Leventhal H, Gonzalez JS, Peyrot M, Rubin RR et al. (2005) Diabetic peripheral neuropathy and depressive symptoms. Diabetes Care 28(10): 23782383.

70. Anderson RJ, Freedland KE, Clouse RE, Lustman PJ (2001) The prevalence of comorbid depression in adults with diabetes. Diabetes Care 24(6): 1069-1078.
71. Chong S, Ding D, Byun R, Comino E, Bauman A, et al. (2017) Lifestyle Changes after a Diagnosis of Type 2 Diabetes. Diabetes Spectrum 30(1): 43-50.

72. Feleke SA, Alemayehu CM, Adane HT (2013) Assessment of the level and associated factors with knowledge and practice of diabetes mellitus among diabetic patients attending at Felege Hiwot hospital, Northwest Ethiopia. Assessment 2(6): 110-120.

73. Adibe M, Aguwa C, Ukwe C, Okonta J, Udeogaranya OP (2009) Diabetes self-care knowledge among type 2 diabetic outpatients in south-eastern Nigeria. Int J Drug Dev Res 1(1): 85-104.

74. Moodley L, Rambiritch V (2007) An assessment of the level of knowledge about diabetes mellitus among diabetic patients in a primary healthcare setting. South African Family Practice 49(10): 16-16d.

75. West JD, Goldberg KL (2002) Diabetes self-care knowledge among outpatients at a Veterans Affairs medical center. Am J Health Syst Pharm 59(9): 849852.

76. Williamson GM (1998) The central role of restricted normal activities in adjustment to illness and disability: A model of depressed affect. Rehabilitation Psychology 43(4): 327-347.

77. Heidrich SM, Forsthoff CA, Ward SE (1994) Psychological adjustment in adults with cancer: The self as mediator. Health Psychology 13(4): 346-353.

78. Aljoudi AS, Taha AZ (2009) Knowledge of diabetes risk factors and preventive measures among attendees of a primary care center in eastern Saudi Arabia. Ann Saudi Med 29(1): 15-19.

79. Rafique G, Khuwaja AK (2003) Diabetes and hypertension: public awareness and lifestyle-findings of a health mela. Journal of the College of Physicians and Surgeons--Pakistan: JCPSP 13(12): 679-683.

80. Al-Mahrooqi B, Al-Hadhrami R, Al-Amri A, et al. (2013) Self-reported knowledge of diabetes among high school students in Al-Amerat and Quriyat, Muscat Governate, Oman. Sultan Qaboos Univ Med J 13(3): 392-398.

81. Demaio AR, Dugee O, de Courten M, Bygbjerg IC, Enkhtuya P, et al. (2013) Exploring knowledge, attitudes and practices related to diabetes in 


\section{Nursing \& Healthcare International Journal}

Mongolia: a national population-based survey. BMC Public Health 13: 178.

82. Majumder N, Majumder N, Datta S, Mail I (2013) Knowledge and perception of mothers of under five children regarding etiology of type-II diabetes mellitus in Agartala, Tripura. Health 1(3): 64-70.

83. Mohieldein AH, Alzohairy MA, Hasan M (2011) Awareness of diabetes mellitus among Saudi nondiabetic population in Al-Qassim region, Saudi Arabia. Journal of Diabetes and Endocrinology 2(2): 14-19.

84. Lagunova Z, Porojnicu AC, Lindberg F, Hexeberg S, Moan J (2009) The dependency of vitamin D status on body mass index, gender, age and season. Anticancer Res 29(9): 3713-3720.

85. Wortsman J, Matsuoka LY, Chen TC, Lu Z, Holick MF (2000) Decreased bioavailability of vitamin D in obesity. Am J Clin Nutr 72(3): 690-693.

86. Vimaleswaran KS, Berry DJ, Lu C, Tikkanen E, Pilz S, et al. (2013) Causal relationship between obesity and vitamin D status: bi-directional Mendelian randomization analysis of multiple cohorts. PLoS medicine 10(2).

87. Al-Shoumer KA, Al-Essa TM (2015) Is there a relationship between vitamin $\mathrm{D}$ with insulin resistance and diabetes mellitus? World J Diabetes 6(8): 1057-1064.

88. Chiu KC, Chu A, Go VLW, Saad MF (2004) Hypovitaminosis $\mathrm{D}$ is associated with insulin resistance and beta cell dysfunction. The American journal of clinical nutrition 79(5): 820-825.

89. Pasquali R, Vicennati V, Gambineri A, Pagotto U (2008) Sex-dependent role of glucocorticoids and androgens in the pathophysiology of human obesity. Int J Obes (Lond) 32(12): 1764-1780.

90. Abudawood M, Tabassum H, Ansar S (2017) Assessment of gender-related differences in vitamin D levels and cardiovascular risk factors in Saudi patients with type 2 diabetes mellitus. Saudi Journal of Biological Sciences. 